\title{
Analysis of Peripapillary Retinal Nerve Fiber Layer and Macular Volume in Patients with Multiple Sclerosis, Neuromyelitis Optica Spectrum Disorders, and Healthy Controls Using Spectral Domain Optical Coherence Tomography in a Turkish Cohort
}

\author{
Multipl Skleroz, Nöromiyelitis Optika Spektrum Bozuklukları ve Sağlıklı Kontrollerden \\ Oluşan Türk Kohortunda Peripapiller Retina Sinir Lifi Tabakası ve Maküla Hacminin \\ Spektral Optik Koherans Tomografi ile Değerlendirilmesi
}

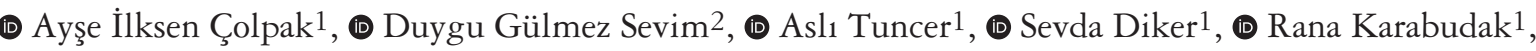 \\ (1) Sibel Kadayıfçılar ${ }^{2}$, (1) Tülay Kansu ${ }^{1}$ \\ ${ }^{1}$ Hacettepe University Faculty of Medicine, Department of Neurology, Ankara, Turkey \\ 2Hacettepe University Faculty of Medicine, Department of Ophthalmology, Ankara, Turkey
}

\begin{abstract}
Objective: To compare the peripapillary retinal nerve fiber layer (pRNFL) thickness and macular volume in patients with multiple sclerosis (MS), neuromyelitis optica spectrum disorders (NMOSD), and healthy controls.

Materials and Methods: This study used spectral domain-optical coherence tomography to measure pRNFL and the volume of retinal layers at the macula. Forty patients with MS or NMOSD and 19 healthy controls were enrolled.

Results: After at least one clinical episode of optic neuritis, the average pRNFL for NMOSD [60 $\mu \mathrm{m}(34-105)]$ and patients with MS [85 $\mu \mathrm{m}(41-109)]$ were lower than in healthy controls $[99 \mu \mathrm{m}(88-109)]$, and patients with NMOSD had significantly lower pRNFL compared with patients with MS (p=0.002). Foveal volume did not differ between optic neuritis eyes of patients with NMOSD and MS (NMOSD $1.18 \pm 0.3 \mathrm{~mm}^{3}$, MS $1.82 \pm 2.07 \mathrm{~mm}^{3}$ ). The mean pRNFL values in seronegative NMOSD eyes $[58 \mu \mathrm{m}$ (range, 47-111)] tended to be thinner compared with seropositive NMOSD eyes [76 $\mu \mathrm{m}$ (range, 42-105)]. This finding was not considered to be statistically significant.

Conclusion: Our study revealed that both foveal (area in a $1.5 \mathrm{~mm}$ ETDRS ring) and total macular volume (area in a $6 \mathrm{~mm}$ ETDRS ring) were lower in both patients with MS and NMOSD compared with healthy controls. Optic neuritis of NMOSD is associated with a thinner average RNFL compared with MS, suggesting earlier axonal injury in the affected optic nerves.
\end{abstract}

Keywords: Neuromyelitis optica, optical coherence tomography, multiple sclerosis, optic neuritis

$\ddot{O} \mathbf{z}$

Amaç: Multipl skleroz (MS), nöromiyelitis optika spektrum bozuklukları (NMOSB) ve sağlıklı kontrollerde, peripapiller retina sinir lifi tabakası kalınlı̆̆ı (pRSLT) ve maküla hacminin karşılaştırılmasıdır.

Gereç ve Yöntem: Bu çalışmada pRSLT ve maküla hacmini ölçmek için spektral optik koherans tomografi kullanılmıştır. MS veya NMOSB nedeniyle izlenen 40 hasta ve 19 sağlıklı kontrol dahil edilmiştir.

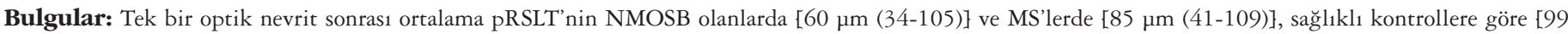
m (88-109)] daha düşük olduğu görülmüş ve bunun NMOSB olanlarda MS'lere göre anlamlı düşük olduğu saptanmıştır ( $\mathrm{p}=0,002)$. Fovea hacmi NMOSB ve MS hastalarının optik nevrit geçiren gözlerinde farklılık göstermemiştir (NMOSB 1,18 $\pm 0,3 \mathrm{~mm}^{3}$, MS 1,82 $\pm 2,07 \mathrm{~mm}^{3}$ ). Ortalama pRSLT kalınlığı seronegatif NMOSB olan grupta [58 $\mu \mathrm{m}$ (47-111)] seropozitif gruba göre [76 $\mu \mathrm{m}$ (42-105)] daha ince olma eğilimde saptanmış olmakla birlikte, bu istatiksel olarak anlamlı bulunmamıştır.

Sonuç: Çalışmamızda sağlıklı kontrollere göre NMOSB ve MS'lilerde hem fovea (1,5 mm ETDRS halkası) hem de maküla (6 mm ETDRS halkası) hacminin azaldığ 1 gösterilmiştir. NMOSB optik nevritinin MS ile karşılaştırıldı̆̆ında, daha ince ortalama RSLT ile ilişkili olduğunu ve etkilenen optik sinirde daha erken aksonal hasar geliştiğini desteklemektedir.

Anahtar Kelimeler: Nöromiyelitis optika, optik koherans tomografi, multipl skleroz, optik nevrit

Address for Correspondence/Yazışma Adresi: Ayşe İlksen Çolpak MD, Hacettepe University Faculty of Medicine, Department of Neurology, Ankara, Turkey Phone: +90 5326945996 E-mail: ilksenisikay@yahoo.com.tr ORCID ID: orcid.org/0000-0002-7444-2640

Received/Geliş Tarihi: 26.05.2018 Accepted/Kabul Tarihi: 05.09.2018

${ }^{\circ}$ Copyright 2019 by Turkish Neurological Society

Turkish Journal of Neurology published by Galenos Publishing House. 


\section{Introduction}

Optical coherence tomography (OCT) is a non-invasive, practical and powerful tool that provides information about the structure of the retina and the head of optic nerves. The technique is mainly based on the differential optical reflectivity and generates a cross-sectional image of the retina, the only visible part of the central nervous system (CNS). OCT provides a quantitative assessment of individual layers of the retina. The retinal nerve fiber layer (RNFL) consists of unmyelinated axons that form the optic nerve after exiting from the lamina cribrosa, and is the main focus of OCT studies. The recent development of spectral domain OCT (SD-OCT) provides shorter acquisition times and enhanced resolution allowing the detection of subtle changes (1).

The pathogenesis of multiple sclerosis (MS) consists of inflammation and early neuroaxonal transection. The rapidly developing technology of OCT aids the detection and monitoring of neuroaxonal degeneration in MS and other CNS diseases such as neuromyelitis optica (NMO) spectrum disorders (NMOSD). The diagnostic criteria of NMOSD have been updated several times since the early optic neuritis $(\mathrm{ON})+$ transverse myelitis complex. The latest defined clinical spectrum involves a wider CNS involvement. The distinction from MS was made after the antibody against water channel protein, aquaporin- 4 has been shown (2). Up to $80 \%$ percent of patients with NMO are seropositive. NMOSD patients have more severe vision loss in acute $\mathrm{ON}$ and poorer visual outcome compared to MS patients and the course of the disease is more aggressive (3). The thinning of peripapillary RNFL (pRNFL) was first described in MS patients in 1999 (4) and NMO patients in 2008 (5).

In this study we aimed to evaluate whether there might be any difference between seronegative/seropositive groups of NMOSD according to OCT findings compared to MS patients and healthy controls. Although the subject itself is not new, knowledge on the pattern of neurodegeneration in the Turkish population may add useful information about general features of NMOSD and MS with and without $\mathrm{ON}$.

\section{Materials and Methods}

\section{Study Design and Patients}

This comparative, observational study was performed at a single referral center. The study and the protocols were approved by the Ethics Committee of Hacettepe University Faculty of Medicine, Ankara, Turkey (KA-120111). Twenty-seven patients with MS and 13 patients with NMOSD (10 seropositive, 3 seronegative) were recruited from Neuro-Immunology and NeuroOphthalmology Clinics of Hacettepe University, between October 2013 to September 2014. Informed consent was obtained from all patients and healthy controls. None of the patients had infectious, vasculitic, ischemic, toxic or hereditary ON. Patients aged older than 18 years who were eligible with a diagnosis of either clinically definite relapsing-remitting MS (RRMS) or NMOSD were included. RRMS and NMOSD diagnoses were made according to revised McDonald criteria and revised diagnostic criteria for NMO, respectively $(6,7)$. Patients with a history of ocular diseases (macular degeneration, uveitis, glaucoma, diabetic retinopathy) and a history of $\mathrm{ON}$ for the past 4 months were excluded. Nineteen age and sex-matched healthy controls with neither ophthalmic nor neurologic diseases were recruited from the headache outpatient clinic or medical staff.

\section{Statistical Analysis}

All patients and controls were examined by the same neurologist and ophthalmologist. Full neuro-ophthalmological assessments including visual acuity (using a Snellen chart), color vision (with Ishihara test), pupillary examination, slit lamp biomicroscopy, and fundoscopy were performed. In addition to standard neuro-ophthalmologic examinations, automatized visual field testing with central 30-2 Swedish Interactive Threshold Algorithm standard program of the Humphrey Field Analyzer (Carl Zeiss Meditec Inc, Dublin, CA, USA) was performed in both eyes of the patients. Retinal layer imaging was performed using a commercial SD-OCT (Spectralis; Heidelberg Engineering, Heidelberg, Germany) device with $\sim 840 \mathrm{~nm}$ wavelength. For SD-OCT, only those images with a signal-to-noise score higher than $25 \mathrm{~dB}$ were analyzed. Scans with misalignment, decentration of the measurement circle, and poor illumination or those out of focus were excluded from the analysis. Average thicknesses were calculated for pRNFL. To assess the pRNFL, a circular scan with a diameter of approximately $3.4 \mathrm{~mm}$ was performed after manually positioning the center on the middle of the optic disc (Figure $1)$. The pRNFL Spectralis protocol generates a map showing the average thickness and maps with 6 sector thicknesses (superonasal, nasal, inferonasal, inferotemporal, temporal, and superotemporal) (8). Macular volumes were quantified using the software of the
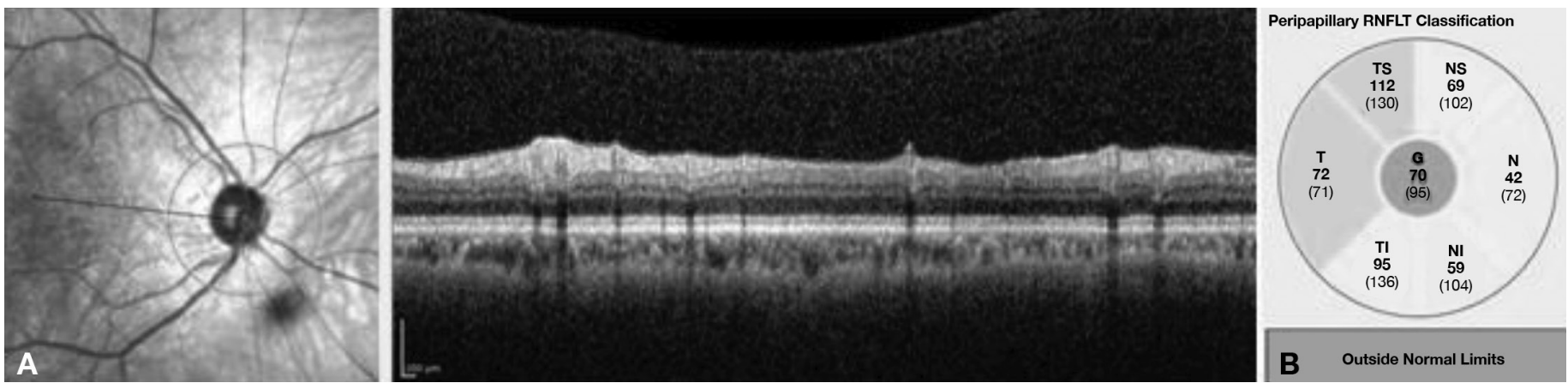

Figure 1. A) Peripapillary retinal nerve fiber layer analysis of the right eye of a patient with multiple sclerosis in a $3.4 \mathrm{~mm}$ circular scan centered on the optic disc. B) Sector distribution 
manufacturer based on the ETDRS protocol (Figure 2). Three retinal volumes were obtained, centered on the foveola with radii of $1.5,3$, and $6 \mathrm{~mm}$. Comparisons of the thickness of retinal layers and macula were performed between $\mathrm{ON}$ and healthy control eyes, between ON subgroups of NMOSD, and MS, and between seronegative and seropositive patients of NMOSD.

\section{Statistical Analysis}

Non-parametric statistical methods were performed due to the small sample sizes; the Kruskal-Wallis test was used to compare the groups and the Dunn test used for pairwise comparisons. A p value of less than 0.05 was considered to be statistically significant.

\section{Results}

The patients' characteristics are described in Table 1. A total of 59 subjects were included in the study, 13 NMOSD (12 females), 27 MS (19 females) and 19 healthy controls (13 females). The mean age of the NMOSD group was $38.1 \pm 11.6$ years, the MS group was 33.0 \pm 9.01 years, and the healthy controls was $34.0 \pm 9.41$ years $(\mathrm{p}>0.05)$. The median disease duration of patients with NMOSD was 4 (range, 1-15) years, and for patients with MS it was 7 (range, 1-21) years. All patients with NMOSD were under immunosuppressive treatment (rituximab $\mathrm{n}=4$, azathioprine $\mathrm{n}=9$ ), and 24 of 27 patients with MS were under disease-modifying treatment (oral $n=2$, parenteral $n=22$ ); the remainder ( 3 patients) was on pulse steroid treatment. Ten of thirteen $(77 \%)$ patients with NMOSD and 20 of $27(74 \%)$ patients with MS had at least one ON episode. The median number of ON episodes for patients with NMOSD and MS were $3(1-9)$ and $2(1-5)$, respectively. The median time between the last ON episode and OCT for patients with NMOSD was 2.5 (range, 1-12) years and for patients with MS it was 7 (range, 1-13) years. Bilateral optic nerve involvement was $50 \%$ for the NMOSD-ON group, $40 \%$ for the MS group, and only 1 patient with NMOSD had simultaneous bilateral ON. Visual acuity of NMOSD-ON eyes (mean 0.6) was worse than non-ON eyes of patients with NMOSD (mean 0.8), MS-ON eyes (mean 0.8) and MS-non-ON eyes (mean 0.8) $(\mathrm{p}<0.01)$.

The mean deviation (MD) indices were used for visual field assessments. The average visual field MD indices were significantly lower in NMOSD-ON eyes $(-14.8 \pm 9.1 \mathrm{~dB})$ compared to NMOSDnon-ON eyes $(-5.5 \pm 4.4 \mathrm{~dB})(\mathrm{p}=0.003)$, MS-ON eyes $(-5.6 \pm 7.8$ $\mathrm{dB})(\mathrm{p}<0.01)$ and MS-non-ON eyes $(-4.4 \pm 3.7 \mathrm{~dB})(\mathrm{p}<0.01)$ (Table 2, 3).

Macular volume did not differ between ON eyes of patients with NMOSD $\left(1.18 \pm 0.3 \mathrm{~mm}^{3}\right)$ and patients with MS $(1.82 \pm 2.07$ $\left.\mathrm{mm}^{3}\right)(\mathrm{p}>0.05)$, but were less in patients with NMOSD and MSON eyes compared with healthy controls $(\mathrm{p}=0.01)$ (Tables 2,3$)$.

\begin{tabular}{|c|c|c|c|c|c|}
\hline Diagnosis & $\begin{array}{c}\text { No. of } \\
\text { subjects }\end{array}$ & $\begin{array}{c}\text { Age (SD) } \\
y\end{array}$ & $\begin{array}{c}\text { Sex } \\
(\mathrm{F} / \mathrm{M})\end{array}$ & $\begin{array}{c}\mathrm{n} \text { of ON eyes/ } \\
\mathrm{n} \text { of non-ON eyes }\end{array}$ & $\begin{array}{l}\text { NMO IgG } \\
\text { positive \% }\end{array}$ \\
\hline NMOSD & 13 & $38.1( \pm 11.6)$ & $12 / 1$ & $15 / 11$ & $76 \%$ \\
\hline MS & 27 & $33.0( \pm 9.01)$ & $19 / 8$ & $28 / 26$ & 0 \\
\hline Healthy controls & 19 & $34.0( \pm 9.41)$ & $13 / 6$ & $0 / 38$ & 0 \\
\hline
\end{tabular}
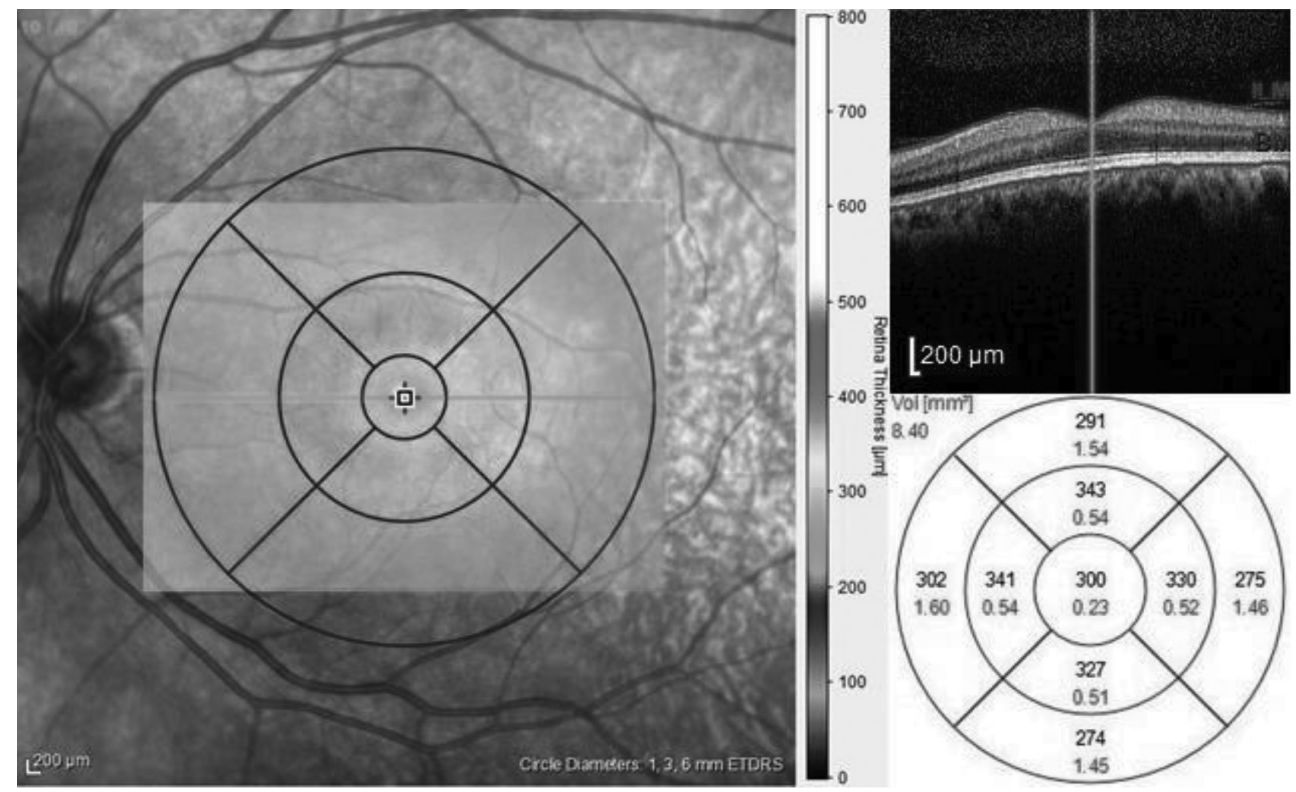

Figure 2. Macular volume analysis of the left eye of a patient in the control group in circle diameters of $1.5,3$ and $6 \mathrm{~mm}$ centered on the fovea 


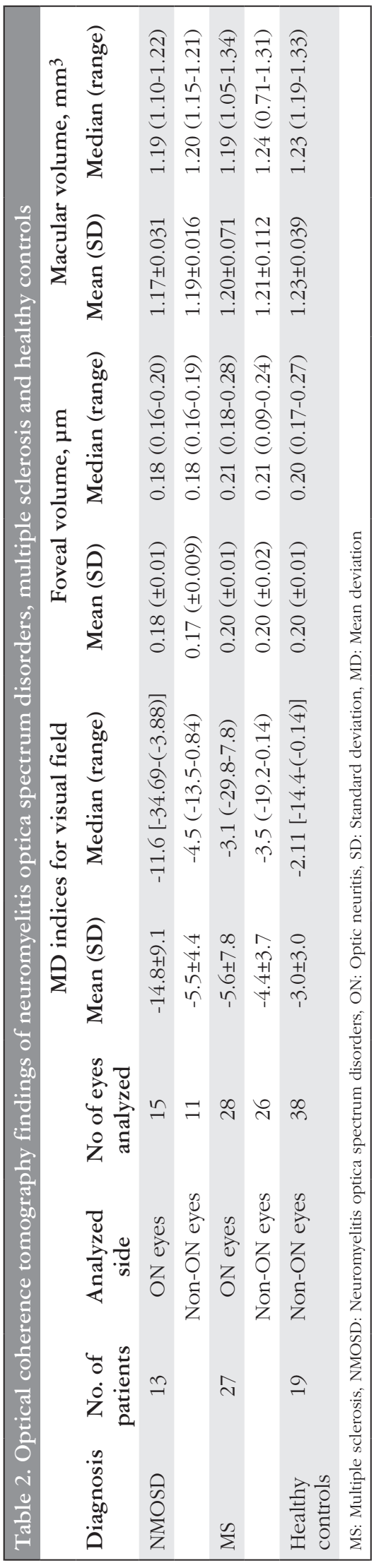

Among ON eyes, patients with NMOSD had a lower foveal volume (FV) of 0.18 (range, $0.16-0.20) \mu \mathrm{m}$ than that of patients with MS (0.21 (range, 0.18-0.28) $\mu \mathrm{m})(\mathrm{p}=0.002)$. FV of non-ON eyes of patients with NMOSD were 0.18 (range, $0.16-0.19) \mu \mathrm{m}$ and less than nonON eyes of patients with MS $[0.21$ (range, 0.09-0.24) $\mu \mathrm{m}\}(\mathrm{p}<0.001)$. Healthy controls had a FV of 0.20 (range, 0.17-0.27) $\mu \mathrm{m}$ (Table 2, 3).

After at least one clinical episode of ON, the mean pRNFL thickness for patients with NMOSD and MS were lower than healthy controls, and patients with NMOSD had significantly lower pRNFL thickness compared with those with MS. Among 43 ON eyes (NMOSD $n=15$, RRMS $n=28$ ), the NMOSD group had a lower mean pRNFL thickness of 60 (range, 34-105) $\mu \mathrm{m}$ compared with the 85 (range, 41-109) $\mu \mathrm{m}$ in MS eyes and 99 (range, 88109) $\mu \mathrm{m}(\mathrm{p}<0.01)$ in healthy controls, and this difference was statistically significant in every quadrant (Table 4). Among patients with MS, eyes with ON showed thinner pRNFL values in all quadrants compared with non-ON eyes, but this difference only reached statistical significance in average values $(\mathrm{p}=0.03)$ (Table 4$)$.

A comparison of the quadrants showed that temporal quadrants were thinner in all patient groups compared with the healthy controls $(\mathrm{p}<0.01)$. Non-ON eyes of the NMOSD group showed a pRNFL thickness of 58.7 (range, 30-81) $\mu \mathrm{m}$ compared with non-ON eyes of patients with MS 59.7 (range, 18-79) $\mu \mathrm{m}(\mathrm{p}=0.2$ not significant) and in comparison with healthy controls 75.5 (range, 57-104) $\mu \mathrm{m}(\mathrm{p}=0.001)$.

Three of 13 patients with NMOSD were seronegative for NMO-immunoglobulin G (23\%). All of these three patients had longitudinal transverse myelitis in addition to ON. One of these seronegative patients had bilateral ON. The average pRNFL values in seronegative NMOSD eyes [58 (range, 47-111) $\mu \mathrm{m}$ ] tended to be thinner compared with seropositive NMOSD eyes $[76$ (range, 42-105) $\mu \mathrm{m}]$, but the difference was not statistically significant $(\mathrm{p}=0.93)$.

Patients with ON showed reduced color vision, and color vision was affected more severely in the NMOSD-ON group compared with MS-ON $(\mathrm{p}=0.004)$. Non-ON eyes of patients with NMOSD and MS showed no difference in color vision ( $\mathrm{p}=0.17)$.

\section{Discussion}

Our primary objective was to compare pRNFL thickness and macular volume between patients with NMOSD, RRMS, and healthy controls, and to evaluate if the severity of pRNFL deficit or macular volume loss could help to distinguish patients with NMOSD earlier in their course of the disease. This cross-sectional study demonstrated that after at least one episode of ON, the thickness of pRNFL was affected in both NMOSD and MS, with temporal quadrants being the most prone areas. We also showed that temporal pRNFL thickness was reduced in patients with NMOSD and RRMS compared with healthy controls, even in patients who had had no previous attack of ON. The study showed that NMOSD was associated with a thinner pRNFL compared with MS, and even temporal pRNFL was thinner in unaffected eyes of both patient groups compared with healthy controls, which was also reported in a study comparing the retinal thickness in the unaffected fellow eyes of MS and AQP4 positive ON patients (9). Furthermore, visual acuity, color vision and visual field indices were more reduced in ON eyes of patients with NMOSD compared with ON eyes of MS. Therefore, our findings showed that visual acuity in the eyes in NMOSD is more deteriorated than in eyes with MS with ON. This

\begin{tabular}{|c|c|c|c|c|}
\hline & $\begin{array}{l}\text { NMO-ON } \\
\text { vs. MS- } \\
\text { ON }\end{array}$ & $\begin{array}{l}\text { NMO-ON vs. } \\
\text { NMO-non } \\
\text { ON }\end{array}$ & $\begin{array}{l}\text { MS-ON vs. } \\
\text { MS-non } \\
\text { ON }\end{array}$ & $\begin{array}{l}\text { NMO non-ON } \\
\text { vs. MS-non } \\
\text { ON }\end{array}$ \\
\hline MD indices for visual field & $0.0001^{\star}$ & $0.003^{\star}$ & 0.7 & $0.0001^{\star}$ \\
\hline Foveal volume & $0.0001^{\star}$ & 0.3 & 0.9 & $0.0001^{\star}$ \\
\hline Macular volume & 0.24 & $0.045^{\star}$ & 0.07 & $0.01^{\star}$ \\
\hline \multicolumn{5}{|c|}{$\begin{array}{l}\text { NMO-ON: Neuromyelitis optica group with optic neuritis, NMO non-ON: Neuromyelitis optica group without } \\
\text { optic neuritis, MS-ON: Multiple sclerosis group with optic neuritis, MS-non ON: Multiple sclerosis group without } \\
\text { optic neuritis, MD: Mean deviation } \\
{ }^{\star} \mathrm{p}<0.05 \text {. }\end{array}$} \\
\hline
\end{tabular}




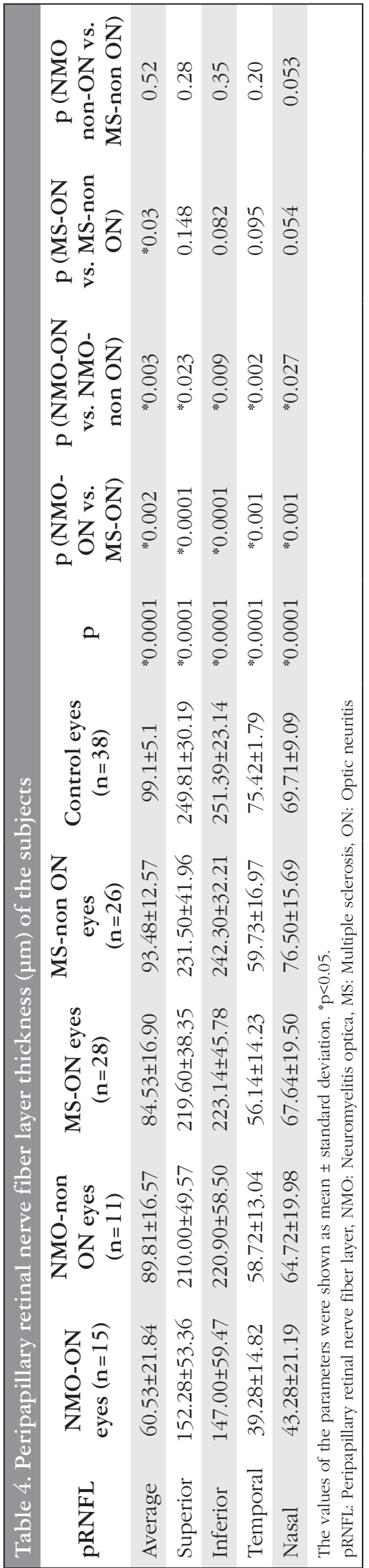

finding may show that $\mathrm{ON}$ in NMOSD causes considerably more harm to visual pathways than MS

Our findings are consistent with previous studies in the literature. Ratchford et al. (10) revealed substantial pRNFL thinning in NMOSD ON eyes relative to both RRMS ON eyes and control eyes, and they also determined more severe visual impairment. The authors found that a first episode of ON in NMOSD was estimated to cause $24 \mu \mathrm{m}$ more loss of pRNFL thickness compared with ON episodes in RRMS. However, they found no difference in OCT parameters between non-ON eyes of RRMS or NMO with healthy controls. In our study, we found that temporal pRNFL thickness was reduced both in non-ON NMOSD and RRMS eyes compared with healthy controls.

In a study by Kersten et al. (11), even though the average pRNFL was normal, they found significant thinning of temporal pRNFL in Huntington disease, which was significantly correlated with the disease duration. They interpreted these findings with the hypothesis that the progression of the disease caused atrophy of the small retinal ganglion cells in the macula, which consequently affected the papillo-macular bundle located on the temporal aspect of the optic nerve that is affected by the disease either directly or as a result of damage to their cell bodies in macula. We think that the reason for finding that the temporal pRNFL thicknesses were reduced in the non-ON group, contrary to Ratchford et al.'s (10) findings, was because they did not study the temporal pRNFL, but average pRNFL instead, which would have shown the earlier signs of damage. In the study of Bichuetti et al. (12), the authors revealed significantly lower levels of average pRNFL in patients with NMOSD compared with RRMS, and found that the pRNFL value of $41 \mu \mathrm{m}$ was $100 \%$ specific for ON associated with NMOSD when compared with RRMS.

In a multicenter study that was performed to outline the disease patterns in seropositive and seronegative NMOSD, seropositive patients were found to have more severe clinical attacks (3). A more severe loss of visual acuity was observed in seropositive patients. However, bilateral ON was more common in seronegative patients, as was simultaneous ON. In the final outcome though, no differences regarding outcomes of $\mathrm{ON}$ were observed between seropositive and seronegative patients (3). Another study comparing seronegative and seropositive groups showed no difference in pRNFL and ganglion cell layer (GCL) thicknesses (13). In our study, we found that seronegative patients had lower average pRNFL values compared with seropositive patients. However, we had only 3 patients in the seronegative group, which would have affected the accuracy of our comparison.

In the study of Park et al. (14), where they used retinal segmentation with SD-OCT, they revealed thinning of GCL plus the GCL + inner plexiform layer at all macular locations in the study groups when compared with healthy controls. These values were lowest in patients with NMOSD. They also found no statistically significant differences when the average pRNFL values were compared between NMOSD, MS, and isolated ON groups, but found significant differences in temporal and inferior pRNFL values.

Recent studies that were mainly focused on Alzheimer's disease and Parkinson's disease showed that, in neurodegenerative diseases, retinal single layer analysis was superior when outlining the retinal pathologies when compared with pRNFL thickness or central foveal thickness alone. These studies indicate that retinal pathology could exist as a thinning of neural tissues that can be shown with SD-OCT using retinal segmentation before they reach the optic nerve (15). This is one of the limitations of our study; we did not use retinal segmentation and evaluate retinal single layer thicknesses because whole retinal thickness or pRNFL analysis alone may not show the earlier results in neurodegeneration. Another limitation is that we did not consider the disease durations and small sample sizes, especially for the seronegative NMOSD group.

In our study, ON was shown to cause a significant decrease in MD of VF (from $-5.5 \pm 4.4 \mathrm{~dB}$ to $-14.8 \pm 9.1 \mathrm{~dB}$ ) in patients with NMOSD; however, patients with MS ON did not cause a statistically significant decline in those parameters. This supports the view that an attack of $\mathrm{ON}$ seems to cause more deterioration of the visual pathways in NMOSD compared with MS. Park et al. (14) also revealed a decline in MD levels in all groups of NMOSD, MS, and isolated ON groups, with the worst results being in the NMOSD group.

Our study revealed that both foveal (area in a $1.5 \mathrm{~mm}$ ETDRS ring) and total macular volume (area in a $6 \mathrm{~mm}$ ETDRS ring) were lower in both patients with MS and 
NMOSD compared with healthy controls. Besides, although not statistically significant, patients with NMOSD had thinner macular volumes compared with patients with RRMS $(1.18 \pm 0.3$ vs $1.82 \pm 2.07 \mathrm{~m}^{3}$, respectively). Ratchford et al. (10) also reported reduced macular volumes in both the NMOSD and RRMS groups compared with healthy controls in their study.

\section{Conclusion}

In conclusion, our results show that both patients with NMOSD and MS with ON have decreased visual acuities, MD indices in VF testing, and pRNFL thickness, the deterioration being more significant in the NMOSD group. These findings suggest that visual pathways are more sensitive to the damage with episodes of $\mathrm{ON}$ in patients with NMOSD. The retina and the optic nerve may be at direct risk due to the existing antibodies. Our results also reveal that even if patients do not undergo ON, damage still exists, especially in pRNFL thickness in both patients with MS and NMOSD, similarly. This is an important issue suggesting that when patients are thought to be clinically silent, there remains an ongoing loss of retinal nerve fibers, suggesting a loss of dopaminergic neurons.

\section{Ethics}

Ethics Committee Approval: The study and the protocols were approved by the Ethics Committee of Hacettepe University Faculty of Medicine, Ankara, Turkey (KA-120111).

Informed Consent: Informed consent was obtained from all patients and healthy controls.

Peer-review: Externally and internally peer-reviewed.

\section{Authorship Contributions}

Surgical and Medical Practices: A.İ.Ç., D.G.S., S.D., A.T., S.K., R.K., T.K., Concept: A.İ.Ç., D.G.S., A.T., Design: A.İ.Ç., D.G.S., A.T., T.K., Data Collection or Processing: A.İ.Ç., D.G.S., Analysis or Interpretation: A.İ.Ç., D.G.S., A.T., Literature Search: A.İ.Ç., D.G.S., Writing: A.İ.Ç., D.G.S., A.T.,

Conflict of Interest: No conflict of interest was declared by the authors.

Financial Disclosure: The authors declared that this study received no financial support.

\section{References}

1. Jindahra P, Hedges TR, Mendoza-Santiesteban CE, Plant GT. Optical coherence tomography of the retina: applications in neurology. Curr Opin Neurol 2010;23:16-23.

2. Lennon VA, Kryzer TJ, Pittock SJ, Verkman AS, Hinson SR. IgG marker of optic-spinal multiple sclerosis binds to the aquaporin- 4 water channel. J Exp Med 2005;202:473-477.

3. Jarius S, Ruprecht K, Wildemann B, et al. Contrasting disease patterns in seropositive and seronegative neuromyelitis optica: A multicentre study of 175 patients. J Neuroinflammation 2012;9:14.

4. Parisi V, Manni G, Spadaro M, et al. Correlation between morphological and functional retinal impairment in multiple sclerosis patients. Invest Ophthalmol Vis Sci 1999;40:2520-2527.

5. Merle H, Olindo S, Donnio A, et al. Retinal peripapillary nerve fiber layer thickness in neuromyelitis optica. Invest Ophthalmol Vis Sci 2008;49:4412-4417.

6. Polman $\mathrm{CH}$, Reingold SC, Banwell B, et al. Diagnostic criteria for multiple sclerosis: 2010 revisions to the McDonald criteria. Ann Neurol 2011;69:292-302.

7. Wingerchuk DM, Banwell B, Bennett JL, et al; International Panel for NMOD. International consensus diagnostic criteria for neuromyelitis optica spectrum disorders. Neurology 2015;85:177-189.

8. Gonzalez-Lopez JJ, Rebolleda G, Leal M, et al. Comparative diagnostic accuracy of ganglion cell-inner plexiform and retinal nerve fiber layer thickness measures by Cirrus and Spectralis optical coherence tomography in relapsing-remitting multiple sclerosis. Biomed Res Int 2014;2014:128517.

9. Akaishi T, Kaneko K, Himori N, et al. Subclinical retinal atrophy in the unaffected fellow eyes of multiple sclerosis and neuromyelitis optica. J Neuroimmunol 2017;313:10-15.

10. Ratchford JN, Quigg ME, Conger A, et al. Optical coherence tomography helps differentiate neuromyelitis optica and MS optic neuropathies. Neurology 2009;73:302-308.

11. Kersten HM, Danesh-Meyer HV, Kilfoyle DH, Roxburgh RH. Optical coherence tomography findings in Huntington's disease: a potential biomarker of disease progression. J Neurol 2015;262:2457-2465.

12. Bichuetti DB, de Camargo AS, Falcao AB, et al. The retinal nerve fiber layer of patients with neuromyelitis optica and chronic relapsing optic neuritis is more severely damaged than patients with multiple sclerosis. J Neuroophthalmol 2013;33:220-224.

13. Matsumoto $\mathrm{Y}$, Mori S, Ueda $\mathrm{K}$, et al. Impact of the anti-aquaporin-4 autoantibody on inner retinal structure, function and structurefunction associations in Japanese patients with optic neuritis. PLoS One 2017;12:e0171880.

14. Park KA, Kim J, Oh SY. Analysis of spectral domain optical coherence tomography measurements in optic neuritis: differences in neuromyelitis optica, multiple sclerosis, isolated optic neuritis and normal healthy controls. Acta Ophthalmol 2014;92:e57-65.

15. Spund B, Ding Y, Liu T, et al. Remodeling of the fovea in Parkinson disease. J Neural Transm (Vienna) 2013;120:745-753. 